\title{
Clinical and Epidemiological Evolution of Sheep Pox in
}

\section{Morocco}

Sara Lafar ${ }^{1,2}$, Khalil Zro ${ }^{2}$, Andy Haegeman ${ }^{3}$, Mounir Khayli ${ }^{4}$, Kris De Clercq ${ }^{3}$, Renaud Lancelot ${ }^{5}$ and My Mustapha Ennaji ${ }^{1}$

1. Laboratory of Virology, Microbiology and Quality/Eco-Toxicology and Biodiversity, Faculty of Sciences and Techniques of Mohammedia, Hassan II University of Casablanca, BP 146, Mohammedia 20650, Morocco

2. Diagnosis, Research and Development Unit, Biological and Pharmaceutical Production Company, BIOPHARMA, BP 4569, Rabat 10000, Morocco

3. Vesicular and Exotic Diseases Unit, Virology Department, CODA-CERVA, Groeselenberg 99, Brussels 1180, Belgium

4. National Office of Health and Food Products Security, ONSSA, Rabat 10000, Morocco

5. CIRAD, Baillarguet International Campus 34398, Montpellier Cedex 5, France

\begin{abstract}
Sheep pox is an infectious viral disease that affects specifically sheep and it is caused by the Capripoxvirus genus. The clinical signs include fever, diarrhea, difficulty breathing, nodules, lung lesions and death. In Morocco, the 2010 epidemic of sheep pox was characterized by the emergence of a nodular form of the disease. The local strain was isolated and the analysis of affected animals was positively confirmed by virus isolation and real-time polymerase chain reaction (RT-PCR). The epidemiological analysis of 911 data records showed that the virus is endemic in the country; an average of 350 cases per year with an epizootic evolution was observed in 2010. The incidence varies depending on provinces and the disease appears confined to the central and the eastern regions of the country where a very intensive sheep breeding activity is taking place. The statistical analysis showed that there is a positive correlation between the endemicity and the significant factor of the rural market $(p=0.006)$. The annual average morbidity and mortality rates were $2.96 \%$ ( $1.26 \%$ to $4.32 \%)$ and $0.71 \%(0.41 \%$ to $0.94 \%)$, respectively. The clinical findings associated to the epidemiological data analysis confirmed the presence of sheep pox in its nodular form and suggest that new pathogenic strains may have been introduced from Mauritania. The purpose of this work was to provide a better description of the spatiotemporal evolution of sheep pox disease based on some epidemiological indicators and to put forward plausible hypotheses regarding the emergence of the virus in order to implement an adequate control strategy.
\end{abstract}

Key words: Sheep pox, Capripoxvirus, epidemiology, clinical signs, virus isolation, RT-PCR.

\section{Introduction}

Sheep pox is a highly contagious infectious disease that affects small ruminants specially sheep [1]. It is caused by sheep pox virus (SPPV) which belongs to the Capripoxvirus genus, the Chordopoxvirinae sub-family belonging to the Poxviridae family [2]. The infection can give rise to a wide variety of clinical signs that may vary according to breed, animal age, immunity and the stress level causing significant

\footnotetext{
Corresponding author: My Mustapha Ennaji, professor, research fields: virology, oncology and medical biotechnologies.
}

economic losses to milk, wool and animal production due to the severe clinical signs and the high mortality and morbidity rates [2]. In Morocco, sheep pox is still the virus responsible for the substantial economic losses in sheep breeding. Its economic impact on livestock in general and on the development of small ruminant meat industry in particular, is highly important. Indeed, the adoption of new approaches to the ranking constraints, based on the analytic hierarchy process of animal diseases in terms of their impact across the sector, showed that sheep pox was among the diseases that hinder livestock development 
in Morocco [3]. However, during the 2010 epidemic in the eastern region of the country, the appearance of a new severe form of the disease called the nodular form was noted for the first time in Morocco, moreover, it has already been reported in Mauritania and reproduced via animal experimental inoculation by SPPV strains isolated in some countries in West Africa. The epidemiological evolution of the disease is related to the importance of the level of sheep immunity which is conditioned by a regular vaccination program. Indeed, during 1970 and 1980 in Morocco, the control strategy was based on vaccination with an average rate of $50 \%$ of the national sheep herd. In the 1990s (1995, 1996 and 1997), this coverage rate was gradually improved to reach at least $80 \%$ of animals at the age of vaccination. Starting from 1999, the epidemiological situation of the disease, characterized by a significant decrease of outbreaks and cases number, helped to adopt a regionalized vaccination program restricted to high risk areas, especially in the eastern region of Morocco. The other provinces which were not covered by the vaccination program were therefore considered as healthy surveillance areas. However, the marked resurgence of outbreaks from 2001 made it necessary to re-adopt a generalized vaccination of sheep. Since 2004, the vaccination against sheep pox has been performed every two years and expanded to the whole sheep population and the vaccine used produces an immunity that can last for more than 24 months. In 2008 and 2009, after the declaration of the peste des petits ruminants (PPR) in Morocco, the fight against sheep pox was focused on the management of reported outbreaks. The vaccination became widespread in 2010 and 2011 after the resurgence of a high number of outbreaks, more particularly in 2010, characterized by the appearance of the nodular form of the disease for the first time in Morocco [4, 5]. In this context, the clinical characterization of SPPV, the epidemiological analysis of the disease evolution and the control of animal movement, seem necessary as preliminary and essential steps towards an effective fight against sheep pox in endemic areas. The objective of this work was to highlight the clinical signs of the disease, to study the epidemiological evolution of sheep pox in Morocco, to confirm the presence of the nodular form by virus isolation and real-time polymerase chain reaction (RT-PCR) methods and finally to establish links between the appearance of the new clinical form and the epidemiological parameters collected between 2007 and 2012 in the prospect of improving and developing a more effective control strategy.

\section{Materials and Methods}

\subsection{Data Collection}

The study period extends from 2007 to 2012 and covers all sheep pox outbreaks notified by the veterinary services in the country. The epidemiological data regularly provided by these services, concerning the number of outbreaks, the number of affected animals and the number of deaths by provinces, have been used to conduct an epidemiological analysis to better understand the evolution of the disease in time and space. The database used for this analysis included 911 records.

\subsection{Data Analysis}

In order to better understand the spread of sheep pox, the annual spatial distribution of outbreaks was done and the "hotspot" areas, such as provinces with yearly recurring outbreaks, are identified by using the geographic information software ArcGIS v9.2. The spatial distribution of outbreaks has been compared to that of small ruminants in strategic markets in Morocco. These markets were identified based on the number of livestock in transit, their capacity to attract animals of different regions and the importance of their geographical location in relation to major roads. The Epi-Info v6 statistical software was used to evaluate the relationship between endemicity of sheep pox disease and the existence of strategic markets. The morbidity and mortality rates were calculated 
based on the data recorded by Moroccan veterinary surveillance network of the National Office for Health Security of Food Products (ONSSA). A particular attention was given to the 2010 epidemic during which the nodular form of sheep pox disease was reported for the first time in Morocco and the first outbreak was identified in the border area with Mauritania (province of Oued Ed-Dahab).

\subsection{Sampling and Clinical Investigations}

Herd health investigations were conducted in the eastern region of Morocco in 36 outbreaks declared by farmers and the complete clinical examination was performed on each infected animal. One hundred ten (110) sheep of different breeds Beni Guil, Oulad Jellal, Sardi and their crosses were examined. At the same time, the autopsies were performed on six animals (four lambs and two adults), to describe the different types of post-mortem lesions observed on different organs. The samples collected from different lesions of the body, head, face, lips, tail, skin and internal lesions, were taken for confirmatory diagnosis.

\subsection{Virus Isolation}

The infectious filtrate was obtained by grinding the sample in Phosphate Buffered Saline (PBS) followed by a centrifugation at $600 \times \mathrm{g}$ for $10 \mathrm{~min}$, then filtration through a $0.45 \mu \mathrm{m}$ filter. The virus was isolated on Vero cell line (kidney epithelial cells extracted from an African green monkey) causing a cytopathic effect in 3-4 d. In a $20 \mathrm{~mL}$ flask, the confluent cell layer was infected blindly with $0.8 \mathrm{~mL}$ of the infectious filtrate and incubated at $37^{\circ} \mathrm{C}$ with $5 \%$ of $\mathrm{CO}_{2}$ injection. The cell layer was examined daily until the appearance of the cytopathic effect. The virus suspension was collected and stored at $-80{ }^{\circ} \mathrm{C}$ after repeated freezing and thawing.

\subsection{DNA Extraction}

The swabs were mixed with $2 \mathrm{~mL}$ of $10 \%$ sterile PBS. After vortexing, the liquid obtained was transferred to a sterile tube. The lung nodules were milled using $4 \mathrm{~mL}$ of $10 \%$ sterile PBS and the mixture obtained was centrifuged at 2,000 rpm for $10 \mathrm{~min}$. The supernatant was collected and maintained at $-20{ }^{\circ} \mathrm{C}$ until extraction. The steps were carried out in a class II microbiological safety cabinet and the DNA extraction was performed by the QIAamp DNA Mini Kit from QIAGEN according to the manufacturer's instructions.

\subsection{RT-PCR Assay}

The RT-PCR method developed by Balinsky was used. The reagents were from SensiFAST Kit from Bioline, the reverse primer (5'AGCATTTCATTTCCGTGAGGA3'), the forward primer (5'GGCGATGTCCATTCCCTG3') and the TaqMan probe (5'CAATGGGTAAAAGATTTCTA3'), labeled at the 5 ' end with reporter dyes FAM, were used in the following cycling conditions: an initial denaturation at $95{ }^{\circ} \mathrm{C}$ for $120 \mathrm{~s}$ followed by 45 amplification cycles at $95{ }^{\circ} \mathrm{C}$ for $2 \mathrm{~s}$ and $60{ }^{\circ} \mathrm{C}$ for $60 \mathrm{~s}$. The primers and the probes were synthesized by Operon Biotechnologies GMBH and the assay was run on Cepheid SmartCycler (Cepheid, Inc., Sunnyvale, CA).

\section{Results}

\subsection{Epidemiological Evolution}

The spatiotemporal distribution of outbreaks in Morocco between 2007 and 2012 showed that sheep pox was endemic throughout the country but its incidence varies from province to province and from year to another (Figs. 1 and 2). Most provinces are affected with variable degrees and the pattern of outbreak distribution does not adequately describe the disease distribution. Indeed, the virus was present in almost all provinces, except in some southern provinces. Sheep pox disease seems confined to the central and eastern regions of the country where there is a very intensive sheep breeding activity, while the southern and north-western regions seem to be spared 


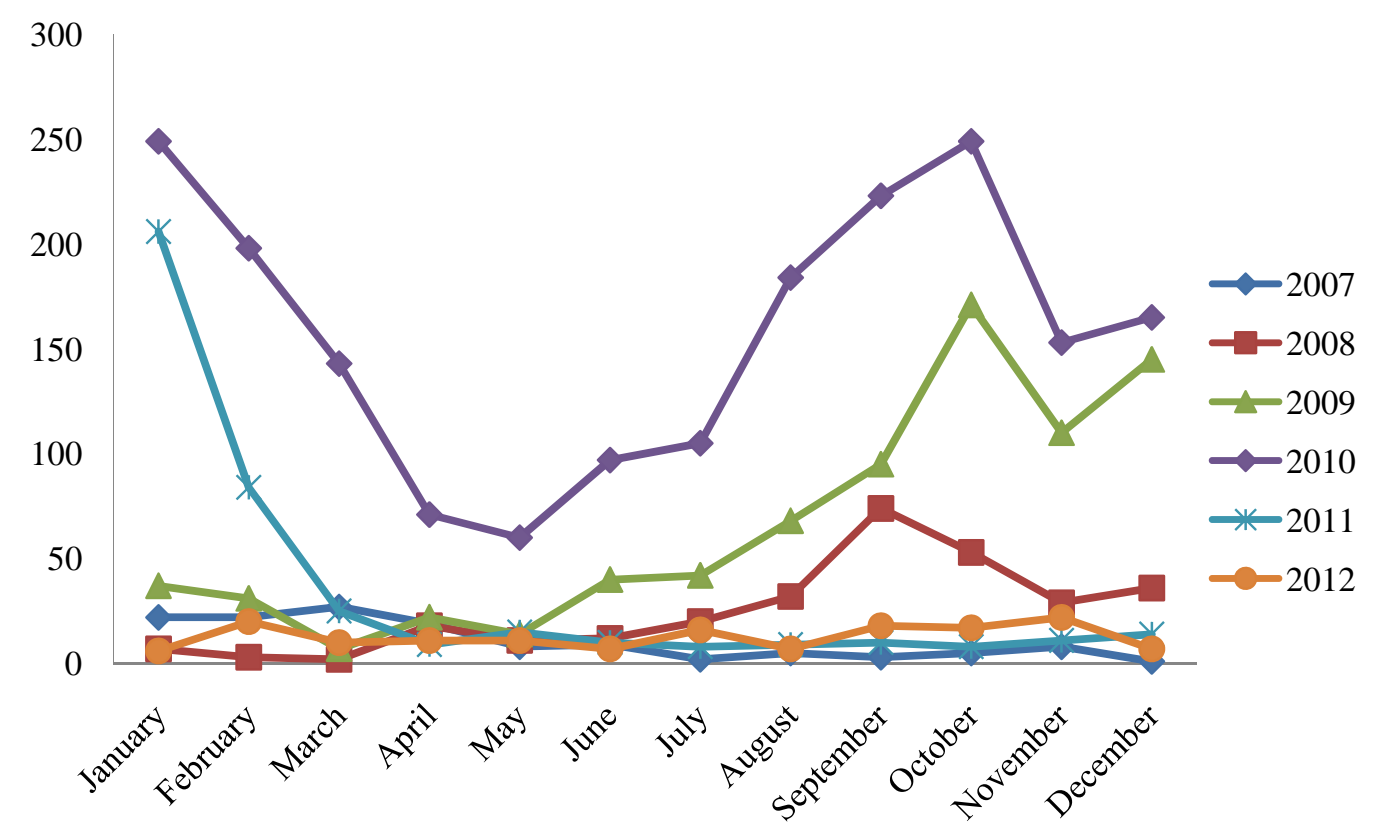

Fig. 1 Temporal distribution of sheep pox outbreaks in Morocco during 2007 and 2012.


Fig. 2 Spatial distribution of sheep pox outbreaks in Morocco during 2007 and 2012.

by a low density of sheep and livestock activity. During 2010, an outbreak of sheep pox was reported for the first time in the southern region of the country, close to the Mauritanian borders. Through the analysis based on the recurrence of sheep pox outbreaks on province scale during the 2007 to 2012, the "hotspots" in which the virus was stably maintained have also been identified. It appears that the virus persists in the 
north-eastern provinces close to the borders with Algeria (Jerrada), in the center of middle Atlas mountains and in the central west regions of the kingdom (Fig. 3). Within a similar "hotspot" province, the spatial distribution of the disease, at the communal level, offered interesting prospects for analysis, particularly regarding the factors determining the concentration of the disease in well-defined geographical locations rather than others. This analysis is crucial for understanding the persistence of these outbreaks despite vaccination campaigns and outbreak declarations and it will also help to provide a basis for a more focused action on animal health surveillance and control. The analysis showed a large number of affected rural communities during 2009 and 2010 (Fig. 4). The recurrence of sheep pox affected

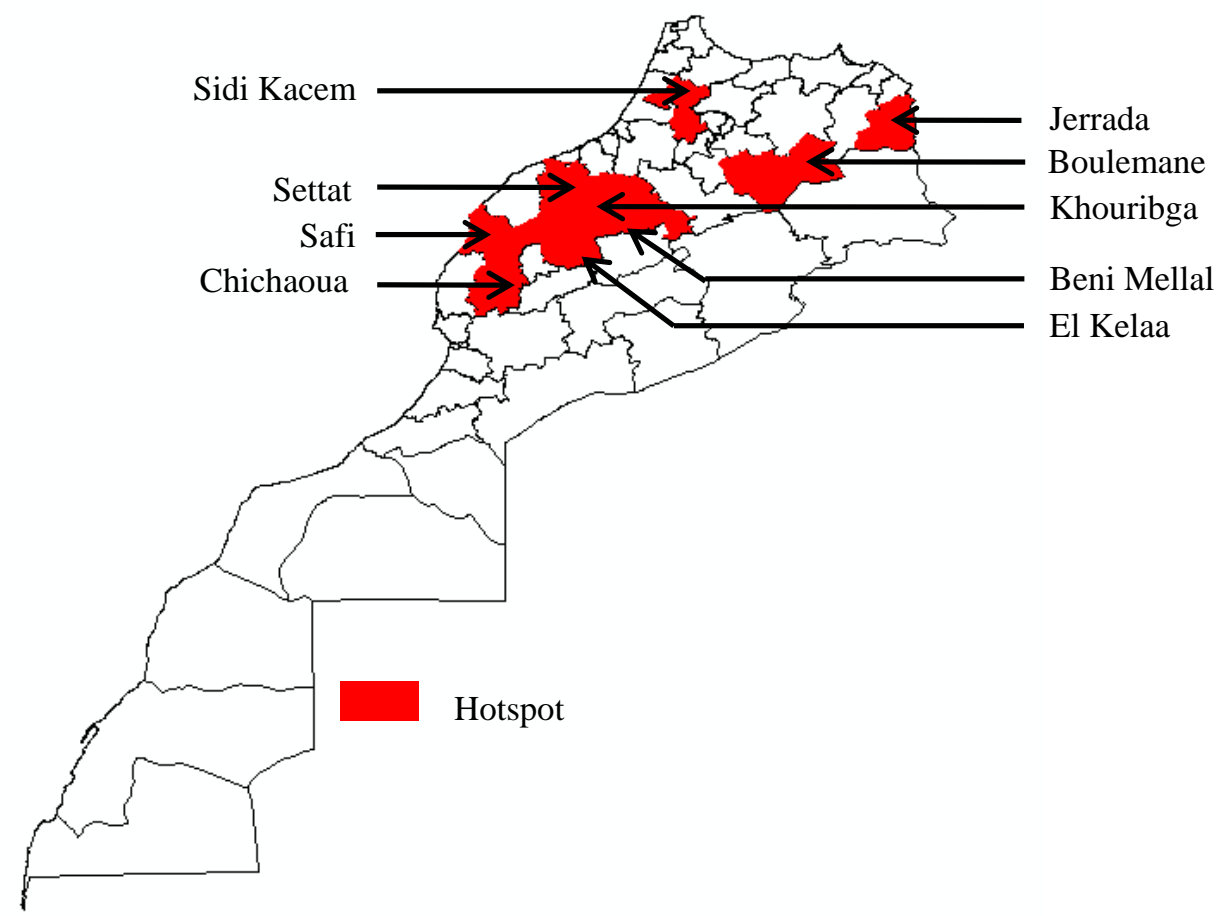

Fig. 3 Distribution of outbreaks “hotspot” by provinces during 2007 and 2012.

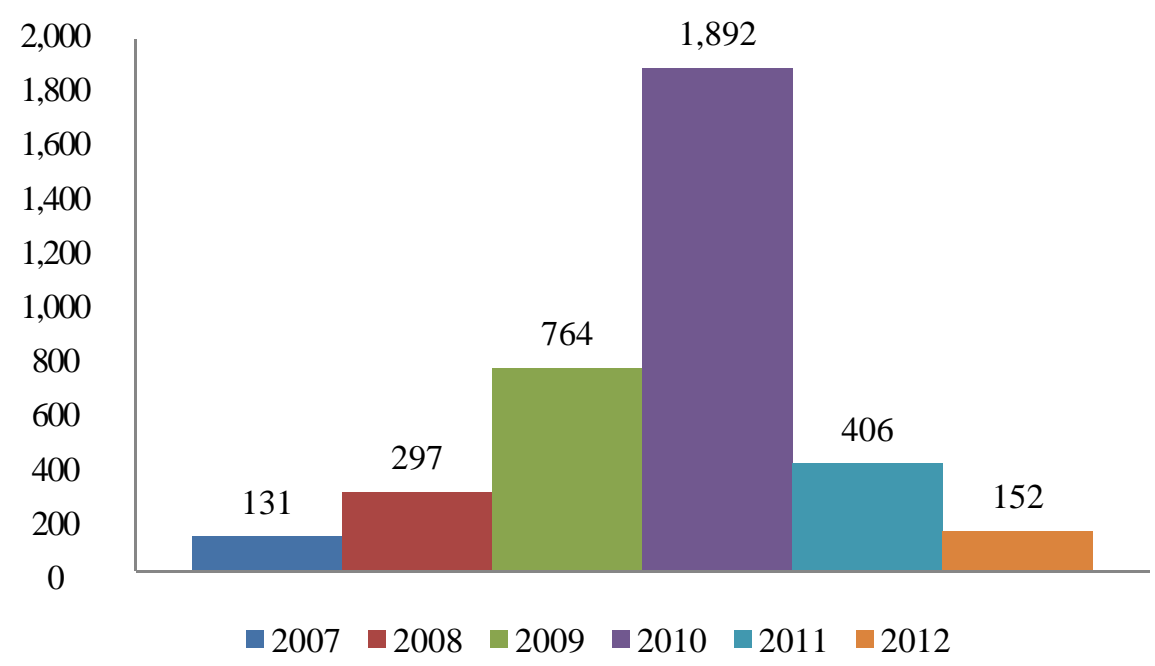

Fig. 4 Sheep pox outbreaks numbers during 2007 and 2012. 
some rural communities, while the outbreak has reached new communities in 2010. The statistical analysis showed that the data set is typically deemed to be statistically significant between sheep pox endemicity and animal rural market which is considered as an exposure factor. The probability of the phenomenon being random is $1 / 20$, resulting in a $p$-value less than $5 \%$. The odds ratio (OR) is greater than 1 , then endemicity is considered to be associated with the animal rural market (OR $=2.93$; $\mathrm{CI}: 1.30$ to $6.80 ; p=0.006$ ).

\subsection{Morbidity and Mortality Data Analysis}

Unlike the evolution of outbreaks, the annual morbidity and mortality rates decreased gradually between 2007 and 2012. The annual average morbidity rate was $2.96 \%$ (1.26\% to $4.32 \%)$ (Fig. 5) and the annual average mortality rate was $0.71 \%$ (0.41\% to $0.94 \%$ ) (Fig. 6); it remains lower than $1 \%$ in each year. Moreover, it seems that despite vaccination around epidemic areas, it did not limit the spread of the disease, but only reduced morbidity and

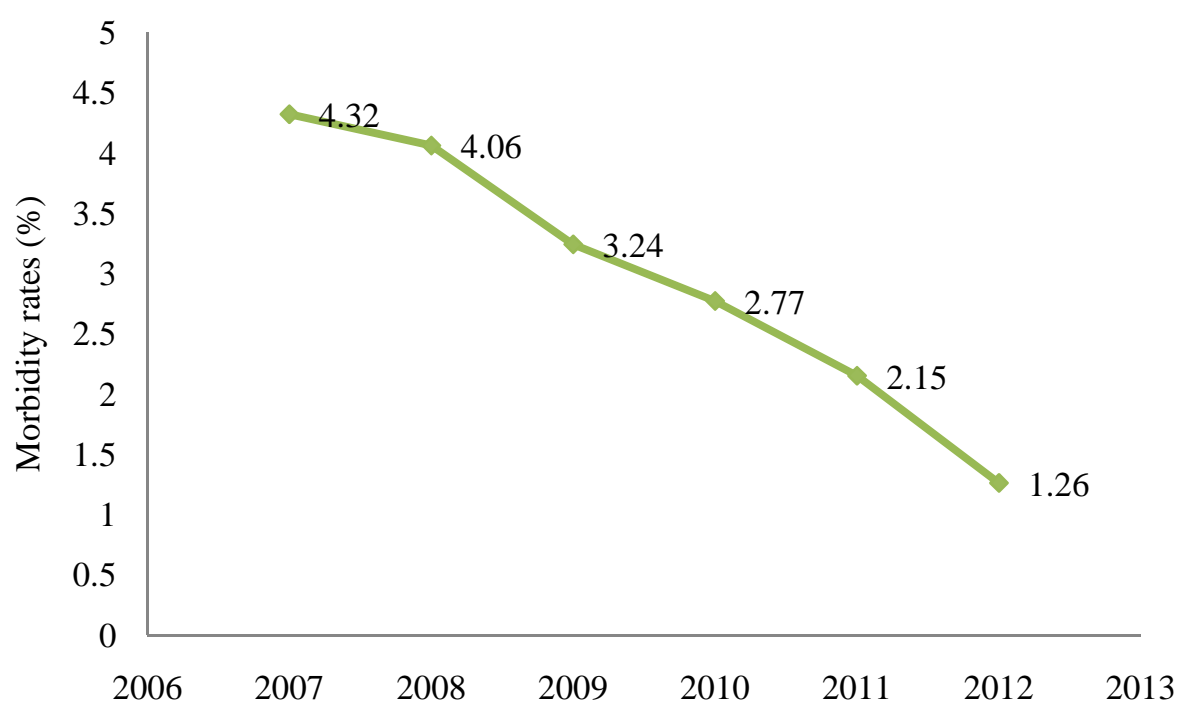

Fig. 5 Morbidity rates during 2007 and 2012.

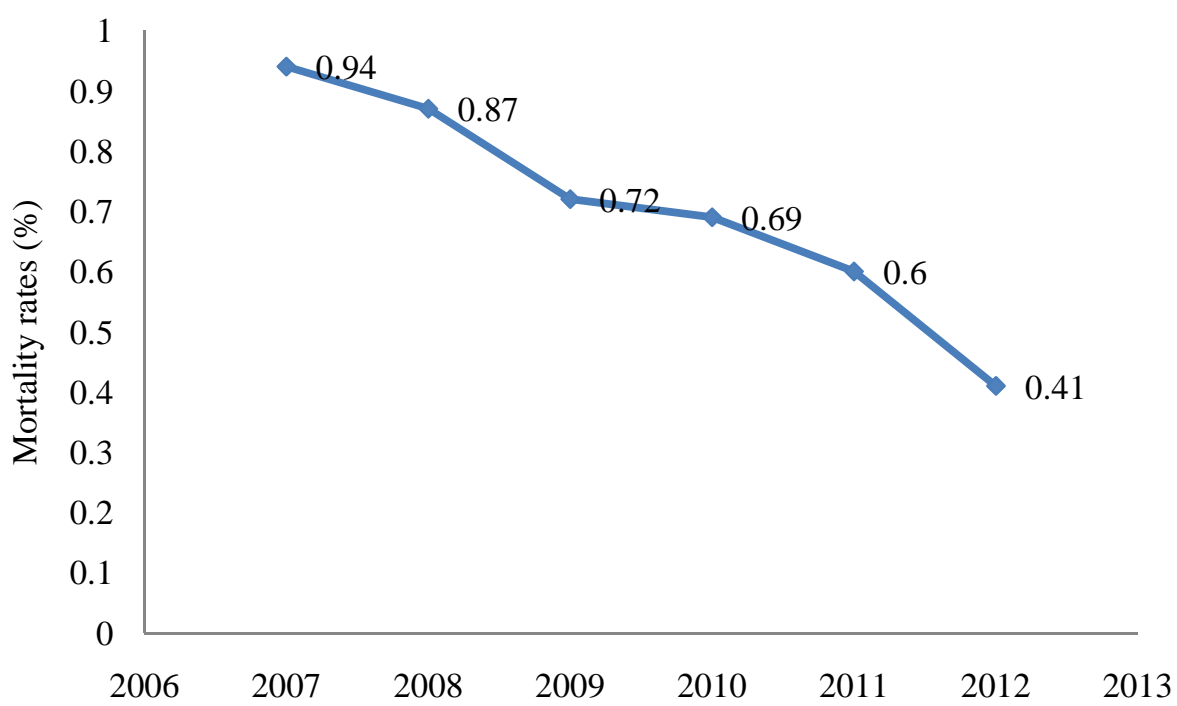

Fig. 6 Mortality rates during 2007 and 2012. 
mortality rates. During 2010 epidemic, the annual morbidity and mortality rates were $3.24 \%$ and $0.69 \%$, respectively. These rates are considered reasonable in an endemic country, but remain below a normal year. Most probably, the measures taken by the veterinary services during 2010 helped to keep the morbidity and mortality rates at a low level, but did not curb the spread of the virus.

\subsection{Clinical Findings and Laboratory Investigations}

The nodular form of sheep pox disease in Morocco is clinically characterized by a general weakening, fever, loss of appetite, depression, nodules, nasal and ocular discharges. The reddish macules (Fig. 7a) appear and quickly change into oval or round erythematous papules with approximately $1-2 \mathrm{~cm}$ in diameter. These papules, most common in clear skinned sheep breeds, such as Sardi and Ouled Jellal, cover in some cases $50 \%$ of the animal body with a most obvious manifestation in hairless areas, particularly under the groin (Fig. 7b), under the tail (Fig. 7c), on the vulva (Fig. 7d), under the arms and legs and on the face, mainly around the muzzle and rarely around the ears. The papules evolve into nodules that can reach $2 \mathrm{~cm}$ in diameter. These nodules coalesce and become larger and hard to the touch, taking the appearance of skin tumors (Fig. 8a). The $100 \%$ of lambs less than four months died while the evolution of skin lesions in older animals (over seven months of age) gave rise to a hairless scar tissue less common in most of affected animals. The autopsies carried out showed the presence of nodules in $100 \%$ of examined lungs. These nodules are firm to the touch, translucent to whitish, embedded in the lung parenchyma, variable in size and may sometimes reach up to few centimeters (Fig. 8b) and bacterial complications are rarely observed. In $100 \%$ of lambs, the nodules are found in the mucosa of the rumen, reticulum, omasum and the abomasum, but they are less apparent in the esophagus. The sub-capsular lesions

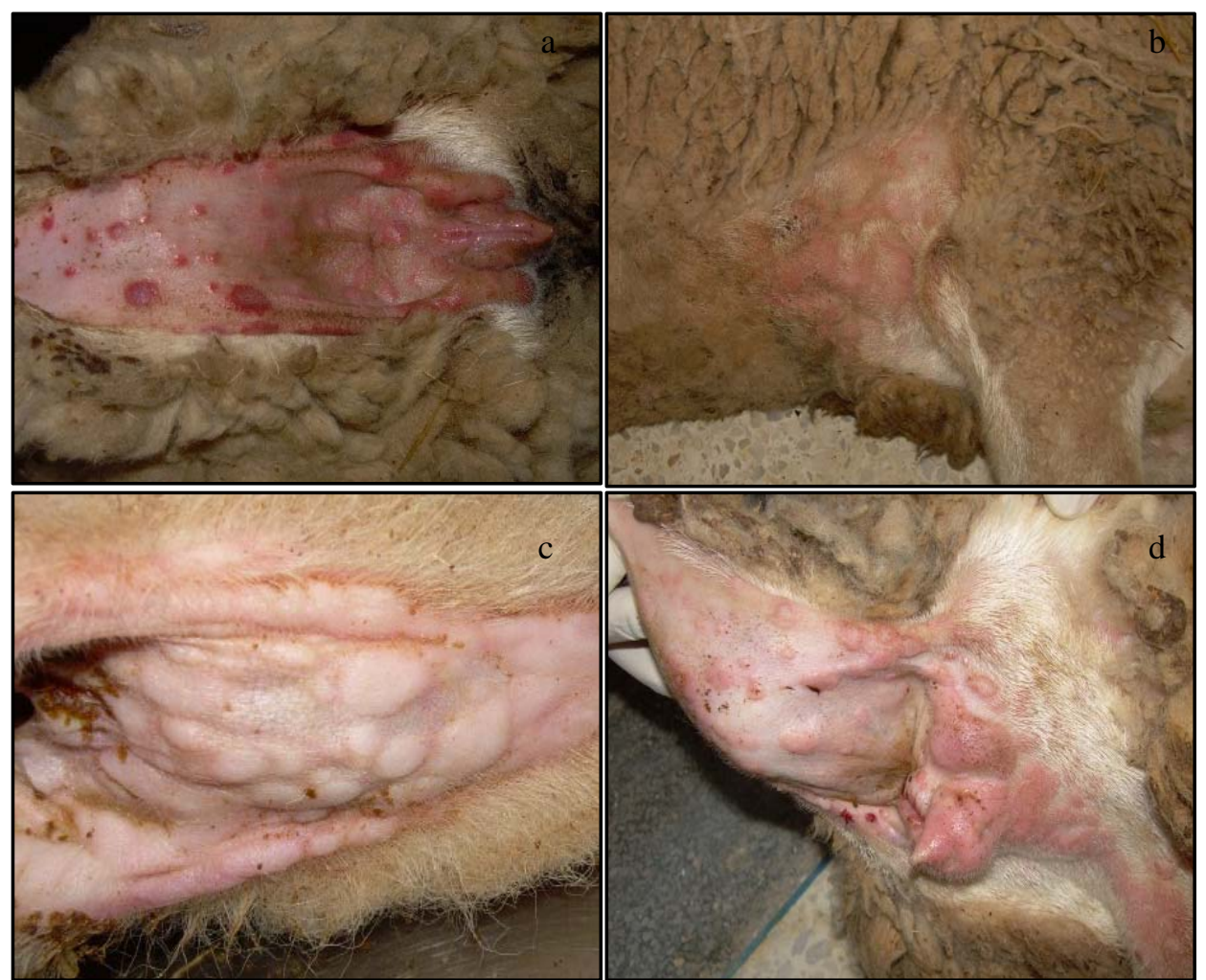

Fig. 7 External clinical characterization of sheep pox: (a) reddish maculae changed to oval erythematous papules, (b) under the groin, (c) under the tail and (d) on the vulva. 


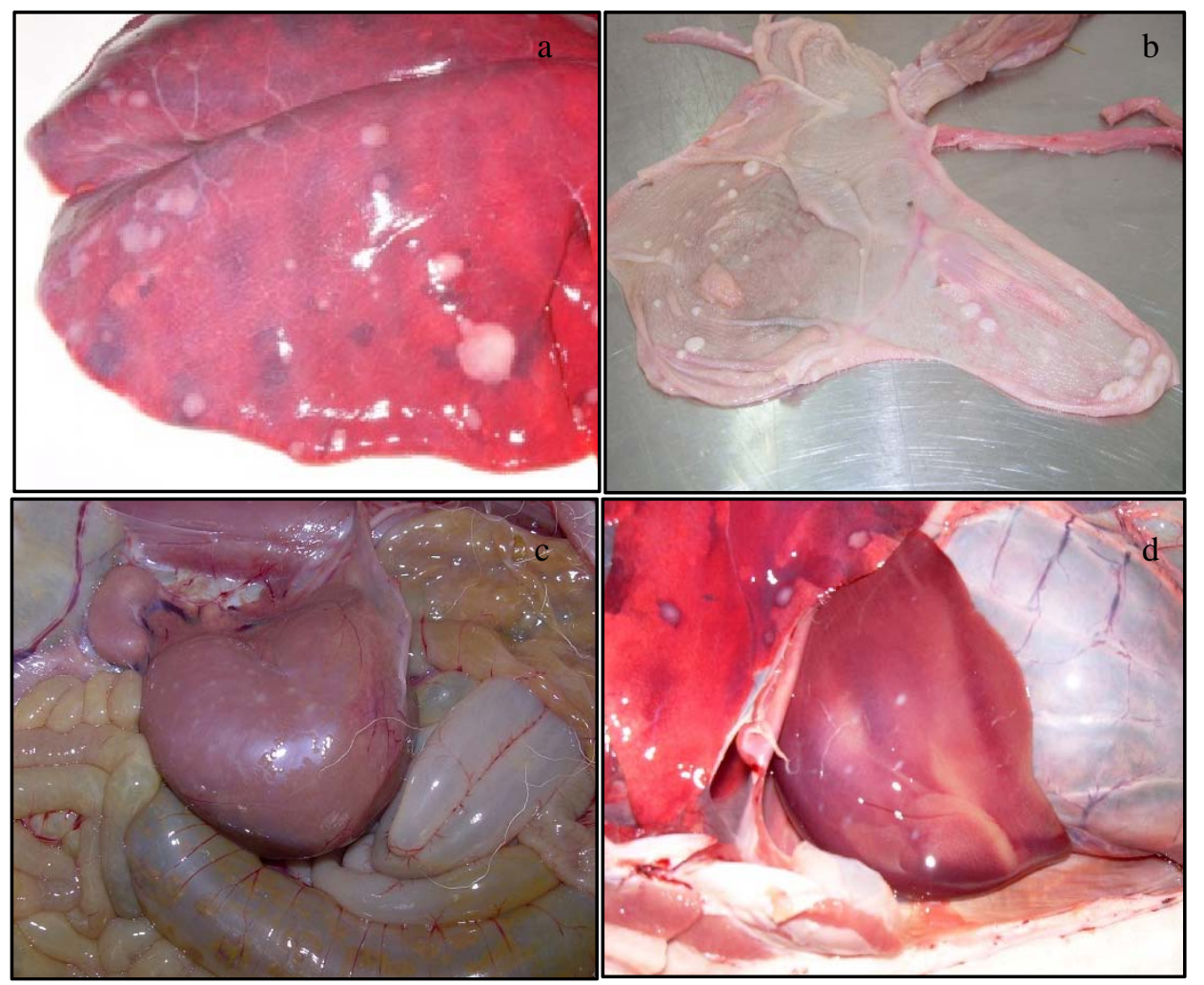

Fig. 8 Internal clinical characterization of sheep pox: (a) nodules taking the appearance of skin tumors, (b) whitish nodules embedded in the lung parenchyma, (c) subcapsular lesions and well-circumscribed nodules observed in the kidney and (d) in the liver.

as small whitish well-circumscribed nodules were observed in 50\% of cases in the kidney (Fig. 8c) and in $30 \%$ of cases in the liver (Fig. 8d). The examination of the sub-epidermal areas revealed, in $100 \%$ of cases, the presence of pink-red circumscribed vascular macules which coalesce causing plaque forms.

\subsection{Virus Isolation and RT-PCR Analysis}

The virus isolation was carried out in Vero cell line and the cythopathic effect was clearly observed after 3-4 d of post-infection and progressed to $80 \%$ after 6 d. The virus demonstrated a high infectious titer of 6.5 $\mathrm{TCID}_{50} / \mathrm{mL}$ after four passages. The RT-PCR assay developed by Balinsky was a rapid, specific and sensitive method that confirmed positively and simultaneously the results of virus isolation and the cycle threshold $(\mathrm{Ct})$ values of analyzed samples were between 14.46 and 20.83. These results indicate that both assays are adequate for SPPV detection from skin scabs, lung nodules, nasal, ocular and rectal swabs.

\section{Discussion}

The reporting of sheep pox outbreaks in Morocco is mainly based on the clinical symptoms. The disease affects specifically sheep and no cases affecting goats were reported. It is characterized generally by fever, lack of appetite and the appearance of lesions on the skin passing through stages of maculae evolving into papules, then into vesicles or vesicular-pustules and finally into dried scabs. The classical vesicular form was usually observed in clinical form of SPPV [6]. However, during the 2010 epidemic, there was an evolution of the clinical aspect into a new nodular form with an intradermal location, in the abomasum, liver, kidneys and lungs, similar to the pattern reported in Mauritania [7] and the findings observed in an animal experimentation through the inoculation of sheep pox strains isolated in some West African countries [8, 9]. This finding has prompted a closer 
examination of all observed cases. The intensity of the clinical expression is influenced by several factors including age, sex, race, bioclimatic conditions and the physiological status of the animal [10]. In this study, the clinical signs are more pronounced in lambs (2-6 months old), even more in females (70\%) than males (30\%) and most common in clear skinned sheep breeds, such as Sardi and Ouled Jellal. Similar clinical findings were also reported by the veterinary services in various regions of the kingdom [4]. A rapid and sensitive diagnostic tool for screening affected sheep flocks is essential. The traditional diagnosis of SPPV is based on the clinical manifestation, virus isolation, serology and electronical microscopy. Among molecular techniques that have been well established for the diagnosis of infectious diseases, PCR has been successfully used for the diagnosis of SPPV and considered one of the best alternatives of conventional assays due to its sensitivity, specificity and reproducibility [11, 12]. The evaluation of conventional types of samples, such as ocular, nasal, rectal swabs, blood, skin scabs and lung nodules, is done by using quantitative PCR [13]. All the studied outbreaks were positively confirmed by PCR and the virus isolation was done only in two outbreaks where the animals were succumbed. Although it has been shown that Capripoxvirus strains circulate between sheep and goats, some strains can be pathogenic for both species with a variable degree of severity in one species more than the other. In Morocco, only sheep present the clinical signs of the disease [14-17]. Sheep pox outbreaks have been reported regularly in different parts of the world. The disease was endemic in the center and the north of Africa, the Middle East and India [17]. In Africa, it was reported from time to time in different countries: Sudan [18], Nigeria [19], Kenya [20], Ivory Coast [21], Senegal [22], Mauritania [7], Algeria [23] and Tunisia [24]. In Morocco, it should be noted that despite the different control measures undertaken for many years by the veterinary services, the disease continues to persist in an enzootic form due to the regular and significant number of sheep pox cases recorded annually (an average of 350 per year). Generally, the evolution of sheep pox curve between 2007 and 2012 showed largely disparate annual variations. A review of the epidemiological data collected during this period showed that sheep pox is endemic with an epizootic peak in 2010. The widespread vaccination campaign of 2007, despite a coverage rate of over $80 \%$ [4], failed to reduce and control the number of disease outbreaks. This evolution could be linked to the incursion of another pathogenic strain from Mauritania. This hypothesis is substantiated by the appearance of the nodular form of sheep pox for the first time in Morocco and reported for a long time in Mauritania [7]. Considering the evolution of outbreaks, the new incursion of SPPV could only be relatively old (before 2010), just the required time for the virus to reach these regions at a high sheep density. In some regions around the world, sheep pox outbreaks were observed throughout the year with seasonal variations directly influenced by bioclimatic factors [10, 23]. In Algeria, the highest average number of outbreaks was recorded in autumn [23], while in some parts of India, the outbreaks were reported during winter and summer [25]. By contrast, in Mauritania, the evolution is seasonal (October through March) and cyclical [7]. In Morocco, the temporal evolution of sheep pox showed that within annual fluctuations, there are seasonal variations which would probably be assigned to the reproductive cycle of sheep. Indeed, the analysis of the evolution of sheep pox outbreaks between 2007 and 2012 showed that they are mostly recorded during winter and autumn period (February through October). In fact, the lambing season is in October-November. The maternal antibodies disappear in lambs whose age is more than three months and accordingly gives a very sensitive young population while the confinement of animals in stables during winter facilitates the viral transmission especially as the virus can withstand in the environment for months [17]. It 
should be noted that the use of widespread vaccination in 2011 helped to reduce the number of outbreaks and to maintain a certain control of the disease in 2012. However, the strategy adopted between 2008 and 2011, based on vaccination around outbreak areas and application of animal health measures (slaughtering infected animals and disinfection of the barn), turned out to be ineffective in the breeding of small ruminants within Morocco. The proximity of sheep pox infected areas to the communities hosting livestock trading platforms could provide explanatory hypotheses on the determining factors of sheep pox endemicity in those areas. In fact, it seems that the disease distribution, at the community level, tends to concentrate in gatherings of neighboring communities via trading activities (weekly markets). Morbidity and mortality rates vary from region to region and from country to another. During the epidemic in Mongolia, morbidity and mortality reached an average of $14.5 \%$ ( $0.8 \%$ to $34 \%$ ) and $0.6 \%$ ( $0 \%$ to $2.6 \%)$, respectively [26]. In Mauritania, reported morbidity ranged from $10 \%$ to $15 \%$, while mortality was less than $5 \%$ [7]. In Mali, mortality rate of $23.3 \%$ (over 60 cases) was attributed to sheep pox [27]. These rates are generally higher in lambs, the immunologically naïve animals and the animals with concurrent infections as well as in pure and cross breeds [28]. In Morocco, the annual average mortality rate was $0.71 \%(0.41 \%$ to $0.94 \%)$; it remains lower than $1 \%$ in each year. Morbidity and mortality rates may account for underreporting of cases and trivialize the measures that farmers should take to prevent the spread of the disease. Awareness raising and training of farmers are the key factors to take into account when developing the strategy for fighting sheep pox.

\section{Conclusions}

Sheep pox is an endemic disease in Morocco which occurs in an epidemiological context marked by the emergence of other contagious diseases including the bluetongue and the PPR. The clinical symptoms observed are those of the nodular form. Therefore, it is important to keep in mind the possible coexistence of two clinical forms of sheep pox in Morocco, the classical vesicular form and the nodular one. The 2010 epizootic sheep pox in Morocco was probably linked to an incursion of pathogenic strains from Mauritania. The understanding of the disease is based on the clinical diagnosis and the knowledge of the epidemiological evolution of the virus. These illustrations are preliminary and a valuable tool for an improved management and control of the disease in Morocco.

\section{Acknowledgments}

The authors would like to thank Dr. Abderrahman El Abrak, director of veterinary services of ONSSA for supporting this work, as well as Mrs. Naoual Skiredj and Naima Galzim for their technical assistance.

\section{References}

[1] Gitao, C. G., Mbindyo, C., Omani, R., and Chemweno, V. 2017. "Review of Sheep Pox Disease in Sheep.” Journal of Veterinary Medicine and Research 4 (1): 1068.

[2] Rashid, P. M. A., Sheikh, B. M. O., Raheem, Z. H., and Marouf, A. S. 2017. "Molecular Characterization of Lumpy Skin Disease Virus and Sheep Pox Virus Based on P32 Gene.” Bulgarian Journal of Veterinary Medicine 20 (2): 131-40.

[3] FAO-Sub Regional Office for North Africa. 2010. Report on a Participatory Analysis of the Constraints Affecting Small Ruminant Meat Sector in Morocco, 14-7.

[4] National Office for the Safety of Food Products (ONSSA). 2014. "Sheep Pox in Morocco." http://www.onssa.gov.ma/fr/sante-animale/programme-de -prophylaxie/clavelee-ovine.

[5] Zro, K., Zakham, F., Melloul, M., El Fahime, E., and Ennaji, M. M. 2014. "Sheep Pox Outbreak in Morocco: Isolation and Identification of Virus Responsible for the New Clinical Form of Disease.” BMC Veterinary Research 10 (1): 31.

[6] Benkirane, A., Fassi Fehri, M. M., and El Idrissi Hamzi, A. 1989. "Main Infectious Diseases of Goats in Morocco with Particular Reference to Contagious Agalactia and Fever Charbonneuse." Humans, Lands and Waters 19 (76): 39-45. 
[7] Le Jan, C., Thiemoko, C., Sow Abdou, D., François, J. L., and Diouara, A. 1987. "Observations on Sheep Pox in Mauritania.” Revue of Livestock and Veterinary Medicine in Tropical Countries 40 (3): 211-4.

[8] Afshar, A., Bundza, A., Myers, D. J., Dulac, G. C., and Thomas, F. C. 1986. "Sheep Pox: Experimental Studies with a West African Isolate.” Canadian Veterinary Journal 27 (8): 301-6.

[9] Bowden, T. R., Babiuk, S. L., Parkyn, G. R., Copps, J. S., and Boyle, D. B. 2008. "Capripoxvirus Tissue Tropism and Shedding: A Quantitative Study in Experimentally Infected Sheep and Goats.” Journal of Virology 371 (2): 380-93.

[10] Bhanuprakash, V. 2001. "Epidemiology of Sheep Pox Infection in Karnataka, the Analysis of Viral Protein Profiles of Field and Vaccine Strains and Evaluation of Live Attenuated Vaccines.” Ph.D. thesis, University of Agricultural Science Bangalore.

[11] Balinsky, C. A., Delhon, G., Smoliga, G., Prarat, M., French, R. A., Geary. S. J., Rock, D. L., and Rodriguez, L. L. 2008. "Rapid Preclinical Detection of Sheep Pox Virus by a Real-Time PCR Assay.” Journal of Clinical Microbiology 46 (2): 438-42.

[12] Haegeman, A., Zro, Z., Vandenbussche, F., Demeestere, L., Van Campe, W., Ennaji, M. M., and De Clerc, K. 2013. "Development and Validation of Three Capripoxvirus Real-Time PCRs for Parallel Testing.” Journal of Virological Methods 193 (2): 446-51.

[13] Zro, K., Azelmat, S., Bendouro, Y., Kuhn, J. H., El Fahime, E., and Ennaji, M. M. 2014. "PCR Based Assay to Detect Sheep Pox Virus in Ocular, Nasal, and Rectal Swabs from Infected Moroccan Sheep." Journal of Virological Methods 204 (1): 38-43.

[14] Le Goff, C., Lamien, C. E., Fakhfakh, E., Chadeyras, A., Aba Adulugba, E., Libeau, G., Tuppurainen, E., Wallace, D. B., Adam, T., Silber, R., Gulyaz, V., Madani, H., Caufour, P., Hammami, S., Diallo, A., and Albina, E. 2009. "Capripoxvirus G-Protein-Coupled Chemokine Receptor: A Host-Range Gene Suitable for Virus Animal Origin Discrimination.” Journal of General Virology 90 (8): 1967-77.

[15] Babiuk, S., Bowden, T. R., Parkyn, G., Dalman, B., Hoa, D. M., Long, N. T., Vu, P. P., Bieu, D. X., Copps, J., and Boyle, D. B. 2009. "Yemen and Vietnam Capripoxviruses Demonstrate a Distinct Host Preference for Goats Compared with Sheep.” Journal of General Virology 90 (1): 105-14.

[16] Lamien, C. E., Lelenta, M., Goger, W., Silber, R., Tuppurainen, E., Matijevice, M., Luckinsa, A. G., and Diallo, A. 2011. "Real-Time PCR Method for Simultaneous Detection, Quantitation and Differentiation of Capripoxviruses.” Journal of Virological Methods 171
(1): 134-40.

[17] OIE-Biological Standards Commission. 2018. "Manual of Diagnostic Tests and Vaccines for Terrestrial Animals.” In OIE Terrestrial Manual. http://www.oie.int/fr/normes/manuel-terrestre/acces-en-li gne/.

[18] Hajer, I., Abbas, B., Samra, M. T. A., and Abu Samra, M. T. 1988. "Capripoxvirus in Sheep and Goats in Sudan." Revue of Livestock and Veterinary Medicine in Tropical Countries 41 (2): 125-8.

[19] Asagba, M. O., and Nawathe, D. R. 1981. "Evidence of Sheep Pox in Nigeria." Tropical Animal Health and Production 13 (1): 61.

[20] Davies, F. G. 1976. "Characteristics of a Virus Causing a Pox Disease in Sheep and Goats in Kenya with Observations on the Epidemiology and Control.” Journal of Hygiene 76 (2): 163-71.

[21] Angba, A., and Pierre, F. 1983. "Sheep Pox in Ivory Coast: Epidemiology-Diagnosis-Prophylaxis.” Revue of Livestock and Veterinary Medicine in Tropical Countries 36 (4): 333-6.

[22] Sarr, J., Diop, M., and Cissokho, S. 1987. “Current Data of Viral Component in the Etiology of Pneumopathies in Small Ruminants in the Sahelian and Sudano-Sahelian Zone.” National Laboratory for Livestock and Veterinary Research, $N^{\circ} 66 /$ Viro.

[23] Achour, H. A., and Bouguedour, R. 1999. "Epidemiology of Sheep Pox in Algeria." Scientific and Technical Review of the Office International des Epizooties 18 (3): 606-17.

[24] Fakhfakh, E., Le Goff, C., Albina, E., Zekri, S., Seghaier, C., Odisseev, C., Jaafoura, M. H., and Hammami, S. 2005. "Isolation and Molecular Study of Sheep Pox and Contagious Ecthyma Strains in Tunisia.” Revue of Livestock and Veterinary Medicine in Tropical Countries 58 (1-2): 7-14.

[25] Bhanuprakash, V., Indrani, B. K., Hosamani, M., and Singh, R. K. 2006. "The Current Status of Sheep Pox Disease.” Comparative Immunology, Microbiology and Infectious Diseases 29 (1): 27-60.

[26] Beard, P. M., Sugar, S., Bazarragchaa, E., Gerelmaa, U., Tserendorj, S. H., Tuppurainen, E., and Sodnomdarjaa, R. 2010. "A Description of Two Outbreaks of Capripoxvirus Disease in Mongolia.” Journal of Veterinary Microbiology 142 (3-4): 427-31.

[27] Traore, A., and Wilson, R. T. 1988. "Livestock Production in Central Mali: Environmental and Pathological Factors Affecting Morbidity and Mortality of Ruminants in the Agro-Pastoral Systems.” Preventive Veterinary Medicine 6 (1): 63-75.

[28] Belwal, L. M., Nivsarkar, A. E., Mathur, P. B., and Singh, R. N. 1982. "Epidemiology of Sheep Pox." Tropical Animal Health and Production 14 (4): 229-33. 